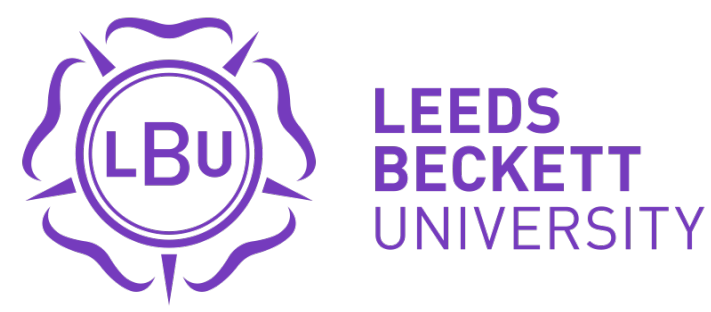

Citation:

O'Hara, J and Brightmore, A and Till, K and Mitchell, I and Cummings, S and Cooke, CB (2013) Evaluation of movement and physiological demands of rugby league referees using global positioning systems tracking. International journal of sports medicine, 34 (9). 825 - 831. ISSN 0172-4622 DOI: https://doi.org/10.1055/s-0033-1333694

Link to Leeds Beckett Repository record:

https://eprints.leedsbeckett.ac.uk/id/eprint/1448/

Document Version:

Article (Published Version)

The aim of the Leeds Beckett Repository is to provide open access to our research, as required by funder policies and permitted by publishers and copyright law.

The Leeds Beckett repository holds a wide range of publications, each of which has been checked for copyright and the relevant embargo period has been applied by the Research Services team.

We operate on a standard take-down policy. If you are the author or publisher of an output and you would like it removed from the repository, please contact us and we will investigate on a case-by-case basis.

Each thesis in the repository has been cleared where necessary by the author for third party copyright. If you would like a thesis to be removed from the repository or believe there is an issue with copyright, please contact us on openaccess@leedsbeckett.ac.uk and we will investigate on a case-by-case basis. 


\section{Evaluation of Movement and Physiological Demands of Rugby League Referees Using Global Positioning Systems Tracking}

Authors

Affiliations

\section{J. P. O'Hara' ${ }^{1}$, A. Brightmore' ${ }^{1}$, K. Till', I. Mitchell ${ }^{2}$, S. Cummings², C. B. Cooke}

${ }^{1}$ Institute for Sport, Physical Activity and Leisure, Carnegie Faculty, Leeds Metropolitan University, Leeds, United Kingdom ${ }^{2}$ Rugby Football League, Red Hall, Leeds, United Kingdom
Key words

match officiating

- movement

physiological demands

accepted after revision December 20, 2012

Bibliography DOI http://dx.doi.org/ 10.1055/s-0033-1333694 Published online:

February 26, 2013

Int J Sports Med 2013; 34: 825-831 @ Georg Thieme Verlag KG Stuttgart · New York ISSN 0172-4622

Correspondence

\section{Dr. John Paul O'Hara, PhD}

Institute for Sport,

Physical Activity and Leisure Carnegie Faculty

Leeds Metropolitan University Headingley Campus LS6 3QS Leeds United Kingdom Tel.: + 44/113/8125 239 Fax: $+44 / 113 / 8127575$ j.ohara@leedsmet.ac.uk

\section{Abstract}

$\nabla$

The use of global positioning systems (GPS) technology within referees of any sport is limited. Therefore, the purpose of the current study was to evaluate the movement and physiological demands of professional rugby league referees using GPS tracking analysis. Time-motion analysis was undertaken on 8 referees using $5-\mathrm{Hz}$ GPS devices and heart rate monitors throughout a series of Super League matches. 44 data sets were obtained with results identifying similar total distance covered between first and second half periods with a significant $(P=0.004)$ reduction in the number of high velocity efforts performed between $5.51-7.0 \mathrm{~m} \cdot \mathrm{s}^{-1}\left(1^{\mathrm{st}}=21 \pm 8\right.$, $\left.2^{\text {nd }}=18 \pm 8\right)$. Mean distance covered from greatest

\section{Introduction}

$\nabla$

Referees in rugby league have the responsibility of regulating the behaviour of the players and enforcing the laws of the game, and can influence the outcome of a game based on their decisions. UK rugby league's national governing body, the Rugby Football League (RFL), employ up to 8 referees on a full-time basis to improve the performance of match officials within Super League (SL). Given the importance of referees to the sport of rugby league it is essential that the demands for both training and performance are given due consideration by sport science.

Rugby league referees have to place themselves in the best possible position to make a decision whilst controlling the $10 \mathrm{~m}$ defensive line. Rugby league referees are more restricted in their positioning compared to soccer referees, who have no restrictions and simply have to place themselves in the best location to make a decision and keep up with the tempo of the game [3]. Research has provided a thorough examination of the move- to least distance, was $3717 \pm 432 \mathrm{~m}, 3009 \pm 402 \mathrm{~m}$, $1411 \pm 231 \mathrm{~m}, 395 \pm 133 \mathrm{~m}$ and $120 \pm 97 \mathrm{~m}$ for the following 5 absolute velocity classifications, respectively; $0.51-2.0 \mathrm{~m} . \mathrm{s}^{-1} ; 2.1-4.0 \mathrm{~m} . \mathrm{s}^{-1}$ : $4.01-$ $5.5 \mathrm{~m} . \mathrm{s}^{-1} ; \quad 5.51-7.0 \mathrm{~m} . \mathrm{s}^{-1} ; \quad<7.01 \mathrm{~m} . \mathrm{s}^{-1}$. Heart rate was significantly $(P<0.001)$ greater in the first $(85.5 \pm 3.4 \% \operatorname{maxHR})$ compared to the second $(82.9 \pm 3.8 \%$ maxHR) half. This highlights the intermittent nature of rugby league refereeing, consisting of low velocity activity interspersed with high velocity efforts and frequent changes of velocity. Training should incorporate interval training interspersing high velocity efforts of varying distances with low velocity activity while trying to achieve average heart rates of $~ 84 \%$ maxHR to replicate the physiological demands.

ment demands of soccer referees e.g., [7,33,34], however only 3 Australasian studies $[13,17,18]$ have evaluated the movement and physiological demands of rugby league referees. Kay and Gill [17] visually analysed video recordings of 5 rugby league referees on 2 occasions from the Australasian National Rugby League (NRL). They found during match play, referees covered a total distance of $6700 \pm 400 \mathrm{~m}$ with $41 \pm 1 \%$ of time spent standing (including stoppages), $25 \pm 4 \%$ jogging, $22 \pm 2 \%$ jogging backwards, $9 \pm 4 \%$ walking, $2 \pm 1 \%$ sideways running and $1 \pm 0.4 \%$ sprinting.

Global positioning system (GPS) analysis has become popular in recent years with researchers evaluating match demands in team sports $[2,14]$. GPS devices have been shown to be a valid, accurate and reliable technology within intermittent exercise, especially when measuring distance covered and peak speeds [4,23]. GPS technology with a higher sampling rate (e.g., $5-\mathrm{Hz}$ vs. $1-\mathrm{Hz}$ systems) has been shown to enhance the validity and reliability of assessing linear and multidirectional movement [27]. Hoare [13] used GPS 
analysis $(1-\mathrm{Hz})$ to examine $10 \mathrm{NRL}$ referees and found total distance covered during match play was $7607 \mathrm{~m}$. Distances reported were $4651 \mathrm{~m}$ walking/slow jogging (below $7 \mathrm{~km} . \mathrm{h}^{-1}$ ), $1651 \mathrm{~m}$ moderate running $\left(7-12 \mathrm{~km} . \mathrm{h}^{-1}\right), 856 \mathrm{~m}$ fast running (12$17 \mathrm{~km} \cdot \mathrm{h}^{-1}$ ) and $443 \mathrm{~m}$ sprinting ( $>17 \mathrm{~km} \cdot \mathrm{h}^{-1}$ ), however no standard deviations were provided. The movement demands in NRL referees produced a mean heart rate of 154 beats. min $^{-1}$ (no standard deviations provided; [13]) or $84.0 \pm 4.0 \%$ [18] of maximal heart rate (calculated from the maximum heart rate achieved in the game). Current research demonstrates the intermittent nature of rugby league refereeing within the NRL only and is limited by the number of observations and analysis performed (e.g., visual analysis of video recordings, 1 -Hz GPS tracking). Previous time motion analysis research in rugby league players has demonstrated different demands exist between the SL (e.g., distance covered $=8503 \pm 631 \mathrm{~m}$; [29]) and the NRL (e.g., distance covered backs $=5573 \pm 1128 \mathrm{~m}$, forwards $=4982 \pm 1185 \mathrm{~m}$; [25]) competitions, providing further rationale for the evaluation of referees from different competitions.

Therefore, the purpose of the present study was to evaluate the movement and physiological demands of rugby league referees using 5-Hz GPS tracking analysis throughout a series of SL matches.

\section{Methods \\ $\nabla$ \\ Study design}

Time-motion analysis was undertaken on a total of 121 European SL matches with 8 referees (between May and October) using portable 5-Hz GPS devices (MinimaxX; Catapult Sports, Australia) and 1-Hz heart rate monitors (Polar Electro, Kempele, Finland). However, only 44 full GPS data sets (36\%) were obtained (mean $5.5 \pm 3.4$ matches per referee, ranging from 1 to 11 games). Before wearing GPS units in match play, the referees underwent a familiarisation period, using the GPS devices during training scenarios to accustom the referees to wearing the GPS devices. Prior to data collection referees completed a standard sub-maximal and maximal exercise test [15] on a motorised treadmill (Woodway ELG70, Woodway, GmBH, Weil am Rhein, Germany) to establish the relationship between oxygen uptake and running speed, as well as maximum heart rate (maxHR (the highest value reached)), respectively. Using regression analysis, oxygen uptake, running speed and maximal oxygen uptake were used to determine variability in relative exercise intensity at each absolute velocity classification boundary for each referee, which are defined below. MaxHR was used to determine percentage heart rate zones during match play, as outlined below.

\section{Participants}

8 full-time professional rugby league referees participated in this study, all with a minimum of 1 year's experience within SL matches. All the registered referees had the same function being full-time, with none of them acting as auxiliary referees. The referees had a mean age of $34.3 \pm 6.5$ years, height of $175.8 \pm 4.7 \mathrm{~cm}$, body mass of $77.3 \pm 6.0 \mathrm{~kg}$, maximal oxygen uptake of $59.8 \pm 5.8 \mathrm{ml} . \mathrm{kg}^{-1} . \mathrm{min}^{-1}$ and maxHR of $184.4 \pm 5.3$ beats. $\mathrm{min}^{-1}$. Procedures and risks were explained prior to the study and all referees gave written informed consent. The protocol employed during this investigation received institutional ethical approval and was performed in accordance with the ethical standards specified by Harriss and Atkinson [12]. Permission to undertake the research was granted by the Rugby Football League Match Officials Director, which was endorsed by the referees themselves who were very interested to understand more about the physiological and movement demands of officiating.

\section{Preliminary testing}

Referees completed a discontinuous incremental exercise test to volitional exhaustion which included a sub-maximal phase and maximal phase to determine maximal oxygen uptake and MaxHR [15]. Upon arrival at the laboratory the referees were fitted with a telemetric heart rate monitor (Polar RS400, Polar Electro Oy, Finland). After a warm-up routine, the referees then completed between five and seven 3 min exercise stages on the motorised treadmill. The starting velocity for each referee for the sub-maximal phase was $9 \mathrm{kmh}^{-1}$ increasing by $1.0 \mathrm{kmh}^{-1}$ each stage, with the treadmill set at a $1 \%$ gradient [16]. When heart rate exceeded $95 \%$ of the predicted maximum or blood lactate exceeded $4 \mathrm{mmol}^{-\mathrm{l}^{-1}}$ the sub-maximal phase of the test was terminated. After 15 min recovery the referees returned to the motorised treadmill to complete the maximal phase of the test. They resumed running at a velocity $2.0 \mathrm{~km} . \mathrm{h}^{-1}$ below their final sub-maximal phase running speed. Treadmill gradient was increased by $1 \%$ every $60 \mathrm{~s}$ until volitional exhaustion. Throughout the test the referees wore a facemask so expired gas could be collected and measured using a MetaLyzer 3B online gas analysis system (Cortex Biophysik GmbH, Germany) to calculate oxygen uptake. The digital tripleV volume transducer was calibrated using a 3-litre syringe (Hans Rudolph Inc, USA) and the gas analysers calibrated using room air and a mass standard gas mixture (Alpha Gravimetric standard, BOC gases, Guildford, UK) of oxygen and carbon dioxide in nitrogen equivalent to expired air $\left(15 \% \mathrm{O}_{2}\right.$ and $\left.5 \% \mathrm{CO}_{2}\right)$. The laboratory was air-conditioned ensuring adequate ventilation and temperature was maintained at $19^{\circ} \mathrm{C}$.

\section{Procedure}

Prior to warming up on match day, the GPS devices were activated. The referees were fitted with an appropriately sized vest which allowed the portable GPS unit to be positioned between the scapulae at the base of the cervical spine. The heart rate monitor was positioned around the chest with a referee shirt worn over the top of the vest. Referees were allocated a GPS unit and heart rate belt for the entire duration of the study [26]. Upon entering the field for warm up the GPS device was fitted within the vest. The MinimaxX GPS (Catapult Sports, Australia) device $(88 \times 50 \times 19 \mathrm{~mm}$ in size, $67 \mathrm{~g}$ in weight $)$, which has been reported to be reliable and accurate $[14,27]$ sampled at a rate of $5-\mathrm{Hz}$ with 3D magnetometers recording at $30-\mathrm{Hz}$ for analysing direction of movement. Research has not established the validity and reliability of analysing direction of movement using the MinimaxX GPS system. However, previous research [20] has used magnetometers to assist in establishing angular rates of rotation [21] as well as animal movement and behaviour [10], which are used for measuring direction of travel within the MinimaxX device. For the 44 matches analysed, mean match duration was $85.4 \pm 3.7 \mathrm{~min}$ $\left(1^{\text {st }}\right.$ half $=42.7 \pm 2.3 \mathrm{~min} ; 2^{\text {nd }}$ half $\left.=42.9 \pm 2.0 \mathrm{~min}\right)$. Match play commenced between $15: 00 \mathrm{~h}$ and $20: 00 \mathrm{~h}$ with data collected at 13 stadia throughout the SL.

\section{Data analysis procedures}

All data were downloaded to a PC and analysed using Logan Plus 4.0 (Catapult Innovations, Australia) software. Exclusion criteria 
for the GPS data included referees not activating the GPS unit, poor or no satellite coverage during the match (minimum of 4 satellites; [31]), loss of satellite coverage during match play, loss of data through battery failure, unit deactivation or software errors. The number of satellites ranged from 4 to 9 (mean = $6.5 \pm 0.9$ with a horizontal dilution of precision of $2.1 \pm 0.5$ ). A low horizontal dilution of precision (within range of $0-50$ ) indicates an optimal geometrical positioning of orbiting satellites for accurate monitoring of position [14,35]. Exclusion criteria for heart rate data included no corresponding GPS data, loss of heart rate data during match play or software errors. This resulted in 44 GPS and 36 heart rate data sets, respectively. Once appropriately formatted, data were exported for analysis in Microsoft Excel 2007 (Microsoft Corporation, USA) for the purpose of data management.

\section{Measures}

Total and relative ( $\mathrm{m} . \mathrm{min}^{-1}$ ) distance covered during match play were examined alongside distances covered per half. The mean frequency of movement 'efforts' (a discrete movement event lasting $0.2 \mathrm{~s}$ before a change in velocity or direction) were classified into 6 velocity categories [28], which were typical of previous time motion analysis in rugby league players [29]. The 6 velocity classifications were standing $\left(<0.5 \mathrm{~m} . \mathrm{s}^{-1}\right)$, walking (0.51-2.0 m.s $\left.\mathrm{s}^{-1}\right)$,jogging $\left(2.01-4.0 \mathrm{~m} . \mathrm{s}^{-1}\right)$, running $\left(4.01-5.5 \mathrm{~m} . \mathrm{s}^{-1}\right)$, high speed running (5.51-7.0 m.s. $\mathrm{s}^{-1}$ HSR) and sprinting $\left(>7.01 \mathrm{~m} . \mathrm{s}^{-1}\right)$. The use of qualitative descriptors for these absolute velocity bands may be confusing, as they may have a different meaning relative to the range of velocities achieved by each individual. For example, high speed running for one individual may be sprinting for another. However, the selected absolute velocity classifications are important for comparison with the literature, and will be used from this point forward rather than using potentially confusing qualitative descriptors. Total mean distance, percentage distance covered, total mean time and percentage of time spent in each velocity classification were calculated. Velocity classifications were further grouped to represent periods of work and rest to provide a work-rest ratio. Based on parameters used in rugby union [5], rest or low intensity activity was classified as activity below $2.2 \mathrm{~m} . \mathrm{s}^{-1}$, whilst effort was classified as activity above $2.2 \mathrm{~m} . \mathrm{s}^{-1}$. The frequency and distance of efforts were also classified into 4 predefined distances (i.e., 0-5 m, 5.01-10 m, 10.01-40 m, >40 m), which were classified by the GPS software, which are common distances observed in rugby league [9]. Movements in facing bands were also considered which included movement in forward, backward, right and left directions. Facing bands were four equal 90 degree quadrant planes (defined by the manufacturer) based on the orientation of the unit and gave distances covered and mean velocities in each direction.

\section{Physiological variables}

Heart rates (beats. $\mathrm{min}^{-1}$ ) were recorded during total match play and for first and second half periods. Percentage heart rates were calculated based on the predetermined maxHR and then categorised into heart rate zones where zone $1=51-60 \% \operatorname{maxHR}$, zone $2=61-70 \%$ maxHR, zone $3=71-80 \%$ maxHR, zone $4=81-90 \%$ maxHR and zone 5=91-100\% maxHR, which are commonly used zones for assessing heart rate $[1,8,32]$.

\section{Statistical analysis}

SPSS version 19.0 was used to conduct analysis with effect sizes $\left(\eta^{2}\right)$ also calculated and statistical significance set at $P<0.05$. Data are presented as mean \pm standard deviations. Preliminary analyses were conducted to check for normality with Kolmogorov-Smirnov tests performed on the data set to check data distribution with $P<0.05$ indicating normality. A paired samples t-test was used to assess differences between first and second half movement and physiological demands. A one-way ANOVA was used to analyse the differences in velocity and movement direction classifications. Coefficient of variation (CV) for the percentage of maximal oxygen uptake at each velocity classification boundary was calculated to assess inter-referee variation in relative exercise intensity.

\section{Results}

$\nabla$

\section{Total and relative distance covered}

The mean total distance covered in match play was $8951 \pm 746 \mathrm{~m}$ (range: 7816-11182m). No significant differences were found between mean distance covered in the first $(4478 \pm 459 \mathrm{~m})$ and second $(4489 \pm 495 \mathrm{~m}$ ) half periods. Based on the mean match duration of $85.4 \pm 3.7 \mathrm{~min}$ the relative distance covered for the total game was $104.8 \pm 10.0 \mathrm{~m} . \mathrm{min}^{-1}$ with no significant difference found between the first $\left(105.0 \pm 11.6 \mathrm{~m} . \mathrm{min}^{-1}\right)$ and second $\left(104.7 \pm 12.6 \mathrm{~m} \cdot \mathrm{min}^{-1}\right)$ half periods.

\section{Velocity classifications and work-rest ratios}

The total frequency of efforts at 4.01-5.5 m.s ${ }^{-1}, 5.51-7.0 \mathrm{~m} . \mathrm{s}^{-1}$ and $>7.01 \mathrm{~m} . \mathrm{s}^{-1}$ was $131 \pm 22$ (range: $75-201$ ), $40 \pm 15$ (range: 16-83) and $10 \pm 7$ (range: $1-32$ ), respectively. The number of efforts in these classifications were maintained (i. e., > $7.01 \mathrm{~m} . \mathrm{s}^{-1}$ $1^{\text {st }}=5 \pm 4,2^{\text {nd }}=5 \pm 4$ ) or decreased in the second half (i.e., $4.01-$ $5.5 \mathrm{~m} \cdot \mathrm{s}^{-1}-1^{\text {st }}=69 \pm 13,2^{\text {nd }}=64 \pm 12$ ) with a significant difference $\left(\mathrm{t}_{1,43}=3.061, P=0.004, \eta^{2}=0.18\right)$ found for efforts between $5.51-$ $7.0 \mathrm{~m} \cdot \mathrm{s}^{-1}\left(1^{\mathrm{st}}=21 \pm 8,2^{\text {nd }}=18 \pm 8\right)$.

- Table 1 shows an overall significant effect for distance covered $\left(F_{5,39}=1105.4, P<0.001, \eta^{2}=0.99\right)$ between each velocity classification with the greatest distance covered between 2.01$4.0 \mathrm{~m} . \mathrm{s}^{-1}(3717 \pm 432 \mathrm{~m})$. For time, an overall significant effect was also evident $\left(F_{5,39}=3914.2, P<0.001, \eta^{2}=0.99\right)$ with a significant difference found between each velocity classification, except activity $<0.5 \mathrm{~m} . \mathrm{s}^{-1}(21.6 \pm 4.4 \mathrm{~min}, 25.3 \pm 4.8 \%)$ and between $2.01-4.0 \mathrm{~m} . \mathrm{s}^{-1}(22.5 \pm 2.3 \mathrm{~min}, 26.3 \pm 2.7 \%)$. Work-rest ratios for total match play were $1: 2.50 \pm 0.37$ with no significant

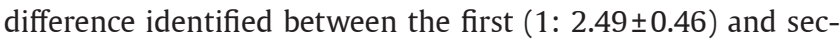
ond ( $1: 2.56 \pm 0.40)$ half work-rest ratios.

A mean total number of efforts of $825 \pm 69$ (range: 697-1026) were identified during match play. Table 2 shows the total number of efforts at each velocity for the 4 predefined distances (i.e., $0-5 \mathrm{~m}, 5.01-10 \mathrm{~m}, 10.01-40 \mathrm{~m},>40+\mathrm{m}$ ). The greatest number of efforts occurred between $0.51-2.0 \mathrm{~m}^{-\mathrm{s}^{-1}}(404 \pm 52)$ with the number of efforts performed decreasing as the velocity increased. However, as velocity increased the number of efforts over longer distances increased with results suggesting a pattern of short distance slow speed efforts with higher speed middle to longer distance efforts occurring during match play.

- Table 3 shows that there is inter-referee variation (CV: 13-33\%) in the relative exercise intensity (percentage of maximal oxygen uptake) across the different absolute velocity classification boundaries. These data suggest that for some referees the veloc- 
Table 1 Mean ( \pm SD) and Range (min-max) for Distance and Time at Each Movement Velocity Classification.

\begin{tabular}{|lcccc} 
Velocity & Distance $(\mathrm{m})$ & \% Distance & Time (minutes) & \% Time \\
\hline$<0.5 \mathrm{~m} \cdot \mathrm{s}^{-1}$ & $294 \pm 57^{*}(199-417)$ & $3.3 \pm 0.7^{*}$ & $21.6 \pm 4.4(12.3-30.3)$ & $25.3 \pm 4.8$ \\
$0.51-2.0 \mathrm{~m} \cdot \mathrm{s}^{-1}$ & $3009 \pm 402^{*}(1350-3771)$ & $34.0 \pm 2.5^{*}$ & $34.5 \pm 3.3^{*}(25.1-41.3)$ & $40.4 \pm 3.9^{*}$ \\
$2.01-4.0 \mathrm{~m} \cdot \mathrm{s}^{-1}$ & $3717 \pm 432^{*}(2729-5174)$ & $41.4 \pm 2.4^{*}$ & $22.5 \pm 2.3(16.3-28.3)$ & $26.3 \pm 2.7$ \\
$4.01-5.5 \mathrm{~m} \cdot \mathrm{s}^{-1}$ & $1411 \pm 231^{*}(767-2183)$ & $15.4 \pm 2.0^{*}$ & $5.2 \pm 0.8^{*}(2.9-7.6)$ & $6.1 \pm 1.2^{*}$ \\
$5.51-7.0 \mathrm{~m} \cdot \mathrm{s}^{-1}$ & $395 \pm 133^{*}(159-685)$ & $4.6 \pm 2.1^{*}$ & $1.2 \pm 0.5^{*}(0.5-2.3)$ & $1.4 \pm 0.5^{*}$ \\
$>7.01 \mathrm{~m} \cdot \mathrm{s}^{-1}$ & $120 \pm 97^{*}(7-488)$ & $1.3 \pm 1.0^{*}$ & $0.5 \pm 0.2^{*}(0.1-1.1)$ & $0.5 \pm 0.4^{*}$ \\
\hline totals & $8951 \pm 746(7816-11182)$ & & $85.4 \pm 3.7(81.1-97.1)$ &
\end{tabular}

Data in parenthesis represent the range for each velocity and respective distance; * Significantly different to all $(p<0.001)$

Table 2 Mean ( \pm SD) and Range (min-max) for the Frequency of Individual Movement Efforts in Total and by Distance in Each Velocity Classification.

\begin{tabular}{lllccc}
\hline Velocity & Total & $\mathbf{0 - 5} \mathbf{m}$ & $\mathbf{5 - 1 0} \mathbf{m}$ & $\mathbf{1 0 - 4 0} \mathbf{m}$ & $\mathbf{4 0 ~ m +}$ \\
$0.51-2.0 \mathrm{~m} \cdot \mathrm{s}^{-1}$ & $404 \pm 52(291-507)$ & $229 \pm 43(137-315)$ & $96 \pm 19(51-142)$ & $78 \pm 14(55-109)$ & $1 \pm 2(0-9)$ \\
\hline $2.01-4.0 \mathrm{~m} \cdot \mathrm{s}^{-1}$ & $240 \pm 30(179-319)$ & $48 \pm 14(24-89)$ & $56 \pm 15(22-92)$ & $124 \pm 17(76-154)$ & $11 \pm 8(3-42)$ \\
$4.01-5.5 \mathrm{~m} \cdot \mathrm{s}^{-1}$ & $131 \pm 22(75-201)$ & $31 \pm 10(14-52)$ & $40 \pm 10(18-69)$ & $58 \pm 13(5-81)$ & $1 \pm 1(0-5)$ \\
\hline $5.51-7.0 \mathrm{~m} \cdot \mathrm{s}^{-1}$ & $40 \pm 15(16-83)$ & $10 \pm 5(4-25)$ & $14 \pm 6(4-34)$ & $16 \pm 7(5-32)$ & $0 \pm 1(0-3)$ \\
$>7.01 \mathrm{~m} \cdot \mathrm{s}^{-1}$ & $10 \pm 9(1-44)$ & $1 \pm 1(0-3)$ & $4 \pm 3(0-11)$ & $5 \pm 4(0-16)$ & $1 \pm 1(0-4)$ \\
total & $825 \pm 69(697-1026)$ & $319 \pm 49(228-442)$ & $210 \pm 30(160-288)$ & $281 \pm 21(219-327)$ & $14 \pm 10(4-53)$
\end{tabular}

Data in parenthesis represent the range for each velocity and respective distance

Table 3 Variation in Percentage of Maximal Oxygen Uptake $\left(\mathrm{ml}^{\mathrm{kg}} \mathrm{kg}^{-1} \cdot \mathrm{min}^{-1}\right)$ at Each Absolute Velocity Classification for Each Referee.

\begin{tabular}{|c|c|c|c|c|c|c|c|c|c|c|}
\hline & 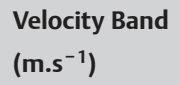 & 0.51 & 2.00 & 2.01 & 4.00 & 4.04 & 5.50 & 5.51 & 7.00 & $>7.01$ \\
\hline \multicolumn{11}{|c|}{ referee } \\
\hline 1 & & 29.7 & 55.1 & 55.3 & 89.8 & 90.0 & 115.9 & 116.1 & 141.9 & 142.1 \\
\hline 2 & & 23.8 & 48.8 & 48.9 & 82.2 & 82.4 & 107.3 & 107.5 & 132.4 & 132.6 \\
\hline 3 & & 13.7 & 51.0 & 51.3 & 101.1 & 101.4 & 138.7 & 139.0 & 176.3 & 176.5 \\
\hline 4 & & 26.5 & 64.1 & 64.4 & 114.7 & 115.0 & 152.6 & 152.9 & 190.5 & 190.8 \\
\hline 5 & & 29.5 & 63.4 & 63.6 & 108.9 & 109.1 & 143 & 143.3 & 174.1 & 177.4 \\
\hline 6 & & 17.8 & 46.5 & 46.7 & 85.0 & 85.2 & 113.9 & 114.1 & 142.8 & 143.0 \\
\hline 7 & & 39.2 & 60.7 & 60.9 & 89.6 & 89.8 & 111.4 & 111.5 & 133.1 & 133.2 \\
\hline mean & & 25.74 & 55.66 & 55.87 & 95.90 & 96.13 & 126.11 & 126.34 & 155.87 & 156.51 \\
\hline SD & & 8.40 & 7.18 & 7.21 & 12.47 & 12.50 & 18.12 & 18.18 & 23.75 & 24.21 \\
\hline CV\% & & 32.63 & 12.91 & 12.90 & 13.00 & 13.00 & 14.36 & 14.39 & 15.24 & 15.47 \\
\hline range & & $13.7-39.2$ & $46.5-64.1$ & $46.7-64.4$ & $82.2-114.7$ & $82.4-115.0$ & $107.3-152.6$ & $107.5-152.9$ & 132.4-190.5 & $132.6-190.8$ \\
\hline
\end{tabular}

ity boundary of $\sim 4.0 \mathrm{~m} . \mathrm{s}^{-1}$ elicits a relative exercise intensity above their maximal oxygen uptake, whereas others are still exercising sub-maximally.

\section{Movement in facing bands}

Movement in 4 facing bands (forward, backwards, left and right) are reported in $\bullet$ Table 4. Significant differences were found for distance covered in the facing bands $\left(F_{3,41}=231.5, P<0.001\right.$, $\eta^{2}=0.92$ ) with all directions significantly different except backwards and left. Referees covered a significantly greater distance in a forward motion. There was an overall significant effect $\left(F_{3,41}=328.1, P<0.001, \eta^{2}=0.90\right)$ for mean velocity in each facing band. Mean velocity was significantly greater in a forward motion and significantly lower for backwards movements. Mean velocities for left and right motion were not significantly different.

\section{Heart rate responses}

- Table 5 shows the heart rate responses for the total, first and second half periods. Heart rate was significantly greater in the first compared to second half period $\left(t_{1,43}=5.008, P<0.001\right.$, $\eta^{2}=0.42$ ). Significant differences were also evident for the time spent between first and second half periods for zone 2 $\left(\mathrm{t}_{1,43}=-2.501, P=0.017, \quad \eta^{2}=0.15\right)$, zone $3\left(\mathrm{t}_{1,43}=-4.524\right.$, $\left.P<0.001, \eta^{2}=0.37\right)$, zone $4\left(t_{1,43}=-4.307, P<0.001, \eta^{2}=0.35\right)$ and zone $5\left(t_{1,43}=7.563, P<0.001, \eta^{2}=0.62\right)$. The percentage of time in zones 2, 3 and 4 were greater in the second half with a greater percentage of time spent in zone 5 (91-100\% maxHR) during the first half.

\section{Discussion}

In recent years the use of GPS technology has become a popular and reliable method of evaluating the movement demands within sport [14]. Based on the lack of research available using GPS tracking in the evaluation of officials within any sport, the purpose of the current study was to evaluate the movement and physiological demands of professional rugby league referees during SL matches. This is the first study to show the movement demands, in terms of distance and velocities, of rugby league referees, with similar demands observed between first and second half periods. The referees covered the majority of distance at velocities between $0.51-2.0 \mathrm{~m} . \mathrm{s}^{-1}$ and $2.01-4.0 \mathrm{~m} . \mathrm{s}^{-1}$, which were interspersed with efforts at higher velocities, thus demon- 


\begin{tabular}{llll} 
Movement & Total Distance $(\mathbf{m})$ & \% Distance & Mean Velocity $\left(\mathbf{m} . \mathbf{s}^{-1}\right)$ \\
forward & $3924 \pm 459^{*}$ & $44.7 \pm 5.8$ & $2.5 \pm 0.1^{*}$ \\
backwards & $1756 \pm 384$ & $19.7 \pm 3.0$ & $1.7 \pm 0.1^{*}$ \\
left & $1518 \pm 375^{*}$ & $16.9 \pm 3.0$ & $1.9 \pm 0.2$ \\
\hline right & $1674 \pm 351$ & $18.8 \pm 2.5$ & $1.9 \pm 0.2$
\end{tabular}

Table 4 Total Distance, \% Distance and Mean Velocity in Facing Bands during Rugby League Refereeing.

*Significantly different to all $(p<0.001)$

\begin{tabular}{|c|c|c|c|}
\hline & $1^{\text {st }}$ Half & $2^{\text {nd }}$ Half & Total \\
\hline average heart rate (beats. $\mathrm{min}^{-1}$ ) & $156 \pm 6$ & $151 \pm 7^{* *}$ & $154 \pm 6$ \\
\hline average heart rate (\%) & $85.5 \pm 3.4$ & $82.9 \pm 3.8^{* *}$ & $84.2 \pm 3.2$ \\
\hline \% time zone 1 (50-60\%) & $0.4 \pm 0.6$ & $0.5 \pm 1.2$ & $0.4 \pm 0.7$ \\
\hline \% time zone 2 (60-70\%) & $2.8 \pm 2.7$ & $4.6 \pm 3.5^{*}$ & $3.6 \pm 2.3$ \\
\hline \% time zone $3(70-80 \%)$ & $13.8 \pm 10.8$ & $18.7 \pm 9.1^{* *}$ & $16.2 \pm 9.5$ \\
\hline$\%$ time zone $4(80-90 \%)$ & $43.8 \pm 15.0$ & $51.1 \pm 12.2^{* *}$ & $47.2 \pm 12.6$ \\
\hline \% time zone $5(90-100 \%)$ & $38.9 \pm 19.8$ & $25.0 \pm 16.9^{* *}$ & $32.0 \pm 17.6$ \\
\hline
\end{tabular}

Table 5 Mean $( \pm S D)$ Heart Rate and Time in Heart Rate Zones for $1^{\text {st }}, 2^{\text {nd }}$ and Total Match Play in Rugby League Refereeing. strating the intermittent nature of the required movement patterns. The inter-referee variation in the percentage of maximal oxygen uptake across the velocity classification boundaries highlights that referees are exercising at very different relative exercise intensities, suggesting marked differences in fitness between these referees. Even though there is some variation in the fitness ability of the referees, which should be taken into consideration, the descriptive data is accurate. Therefore, these findings can be used to enhance specific, intermittent training programmes of rugby league referees that mimic and overload the demands of the game.

The mean total distance covered by referees during match play of $8951 \pm 746 \mathrm{~m}$, was substantially higher than total distances reported in Australasian rugby league referees (7607 m, [13]; $6700 \pm 400 \mathrm{~m}$, [17]) demonstrating SL referees have greater total distance demands than Australasian counterparts. The lack of up to date time motion analysis of Australian referees makes comparisons difficult with further research required analysing the movement demands within the NRL, whereby 2 referees are now utilised. The total distance covered by referees during match play is also greater than that previously reported for rugby league players (Outside-Backs $=6917 \pm 1130 \mathrm{~m}$, Adjustables $=6093 \pm 1232 \mathrm{~m}$, Forwards $=4181 \pm 1829 \mathrm{~m}$; [32]) using GPS analysis. A possible explanation for these findings is game duration with referees officiating for the full match duration, whilst players are often interchanged during the course of a game (e.g., Forwards match duration $=44.2 \pm 19.2 \mathrm{~min}$; [32]).

The lack of difference in the distance covered per half is consistent with previous studies in soccer $[6,20]$ and rugby union [24] referees, but contradicts other soccer referee research [11,22]. A significant decrease in the number of efforts at velocities between $5.51-7.0 \mathrm{~m} . \mathrm{s}^{-1}$ and average heart rate between first and second half periods was apparent, with an increase in the number of lower intensities activities (e.g., 0.51-4.0 m.s $\mathrm{s}^{-1}$ ) during the second half. Fewer higher intensity efforts may be required due to a reduction in match activity of players in the second half period and especially the final quarter (i.e., high intensity running $1^{\text {st }}$ quarter $=22.3 \pm 5.0 \mathrm{~m} \cdot \mathrm{min}^{-1}, \quad 4^{\text {th }} \quad$ quarter $=15.5 \pm 5.4 \mathrm{~m} \cdot \mathrm{min}^{-1}$; [30]). This reduced high intensity activity may therefore explain the lower average heart rate in the second half.

The majority of distance covered and time spent is at velocities below $4.0 \mathrm{~m} . \mathrm{s}^{-1}$ with frequent efforts between $4.01-5.5 \mathrm{~m} . \mathrm{s}^{-1}$ (range: $75-201), 5.51-7.0 \mathrm{~m} . \mathrm{s}^{-1}(16-83)$ and $>7.0 \mathrm{~m} . \mathrm{s}^{-1}(1-44)$ performed during match play. The number of efforts in each velocity classification decreased as the intensity increased, however the distance of efforts increased as intensity increased. These findings demonstrate a constant change of velocity during rugby league refereeing over a range of different distances with on average one sprinting effort over $40 \mathrm{~m}$ occurring per game. These findings can inform conditioning practices for referees, with training combining short distance efforts between $0.51-$ $2.0 \mathrm{~m} . \mathrm{s}^{-1}$, mid to long distance $(5-40 \mathrm{~m})$ efforts between 2.01 $5.5 \mathrm{~m} . \mathrm{s}^{-1}$ interspersed with high intensity efforts $>5.51 \mathrm{~m} . \mathrm{s}^{-1}$ of varying distances. Therefore, the current findings provide the most detailed analysis on the movement demands of rugby league referees.

This is the first study to report the contribution of different directions of movement (e.g., lateral and backwards) to the total distance covered using GPS analysis. The validity and reliability of the magnetometers within the MinimaxX device needs to be established, but the data provides an indication of the directional movement of the referees. Findings demonstrate significantly greater distances and velocities were covered in a forward direction, with lateral and backwards movements substantially contributing to the total distance covered. Comparisons between the current findings and previous notational analysis [17] identified substantial differences between the contribution of lateral movements ( $36 \%$ vs. $2 \%$ of total distance), highlighting a potential issue with the manufacturer's facing band definitions used in the current GPS tracking. Therefore, video footage was reviewed retrospectively and it became apparent that the referees rotate their torso while running in a forwards direction to ensure the best view of the game, rather than performing side stepping movements, which would more traditionally be classified as lateral movement. From these observations, alternative directional definitions were applied to better reflect lateral movement within 7 SL matches. 'Left' and 'Right' movements were reduced to a bandwidth of $30^{\circ}$, which increased the 'Forward' and 'Backward' directional bands to $150^{\circ}$ each. New analysis found $60.3 \pm 7.1 \%$ 'Forward', 28.1 $\pm 4.6 \%$ 'Backwards', $5.3 \pm 1.2 \%$ 'Left' and $6.3 \pm 1.9 \%$ 'Right' of total distance was covered in each direction. This further analysis highlights potential issues with the facing bands used, including the positioning of the GPS unit on the thoracic spine with further research required to establish the correct facing bands to be used within rugby league refereeing to determine the different aspects of multi- 
directional movement. However, training of rugby league referees should in part focus on forward running with rotation of the torso in left and right directions to represent the actions common within match play.

Average heart rate values for referees of $154 \pm 6$ beats. $\mathrm{min}^{-1}$ at $84.2 \pm 3.2 \%$ maxHR are consistent with previous literature $[13,18]$. Findings showed approximately $47 \%$ and $32 \%$ of time was spent between $81-90 \%$ and above $91 \%$ maxHR respectively, which is consistent with findings in soccer referees [19]. These heart rate findings demonstrate that rugby league refereeing is of high intensity and that physiological demands are placed on both the aerobic and anaerobic energy systems during competition. When comparing these physiological responses with the movement demands (i.e., $92 \%$ of time is spent below $4.0 \mathrm{~m} . \mathrm{s}^{-1}$ ), it could be speculated that refereeing would not elicit such large heart rate responses. Previous research suggests that increased heart rates may be associated with psychological factors such as increased stress [19] and anxiety [18] from the high pressure nature of refereeing where decisions are of great importance and could influence the outcome of a game. However, this is yet to be established with these referees and is a possible future research direction. If this was found to be the case then conditioning programmes should not only be based on adhering to specific movement demands but also reflect heart rate responses identified during match play.

This study highlights that it may be problematic to use absolute velocity thresholds with individual referees, as they do not truly reflect the transitions between exercise intensities relative to the fitness of each referee. The velocity threshold used to delineate the boundary between moderate- and high-intensity exercise was $5.5 \mathrm{~m} . \mathrm{s}^{-1}\left(19.8 \mathrm{kmh}^{-1}\right)$ [28]. However, it is clear that for these referees this exercise velocity was supra-maximal relative to maximal oxygen uptake, when estimated using regression analysis. Caution is required as this technique assumes a continued linear relationship between oxygen uptake and running speed. Therefore, this technique is likely to produce some inherent error within the predictions of such relative exercise intensities which are extrapolations beyond maximal oxygen uptake. Even though the heart rate data discussed above provides an overview of the average relative exercise intensity, further research is required using objective physiological measurements to ascertain the transition between individualised low-, moderate-, high- and very high-intensity exercise with rugby league referees.

In conclusion the current study provides the most detailed analysis on the movement and physiological demands of rugby league referees to date. Findings demonstrate highly intermittent movement demands, involving periods of low velocity activity interspersed with short high velocity efforts of differing distance and frequent changes of velocity. However, the use of absolute velocity classifications does not identify transitions between individual relative exercise intensities. Heart rate responses are higher than would be expected for the movement demands and associated psychological factors may increase the physiological responses of officiating. Those responsible for the training and conditioning programmes of rugby league referees should consider using low velocity activity with a rotated torso, some multi-directional (i.e., lateral or backwards) movement interspersed with higher velocity efforts $\left(>5.51 \mathrm{~m} . \mathrm{s}^{-1}\right)$ of varying distances. Additionally, referees should perform training protocols which elicit an average heart rate of at least $~ 84 \%$ maxHR to replicate the physiological demands of officiating.

\section{Acknowledgements}

$\nabla$

The authors would like to acknowledge the contribution of Andy Fairhurst, Steve Worthington, Liam Gallagher and Jack Fahey to the current research study.

\section{References}

1 Borresen J, Lambert MI. Quantifying training load: A comparison of subjective and objective methods. Int J Sports Physiol Perform 2008; 3: $16-30$

2 Brewer C, Dawson B, Heasman J, Stewart G, Cormack S. Movement pattern comparisons in elite (AFL) and sub-elite (WAFL) Australian football games using GPS. J Sci Med Sport 2010; 13: 618-623

3 Castagna C, Abt G, D'Ottavio S. Physiological aspects of soccer refereeing performance and training. Sports Med 2007; 37: 625-646

4 Coutts AJ, Duffield R. Validity and reliability of GPS devices for measuring movement demands of team sports. J Sci Med Sport 2010; 13: 133-135

5 Cunniffe B, Proctor W, Baker JS, Davies B. An evaluation of the physiological demands of elite rugby union using Global Positioning System tracking software. J Strength Cond Res 2009; 23: 1195-1203

6 Di Salvo V, Collins A, McNeill B, Cardinale M. Validation of Prozone: A new video-based performance analysis system. Int J Perform Anal Sport 2006; 6: 108-119

7 D'Ottavio S, Castagna C. Analysis of match activities in elite soccer referees during actual match play. J Strength Cond Res 2001; 15: 167-171

8 Edwards S. The Heart Rate Monitor Book. Sacramento, CA: Fleet Feet Press, 1993

9 Gabbett T, King T, Jenkins D. Applied physiology of rugby league. Sports Med 2008; 38: 119-138

10 Guo Y, Poulton G, Peter Corke, Bishop-Hurley G, Wark T, Swain D. Using accelerometer, high sample rate GPS and magnetometer data to develop a cattle movement and behaviour model. Ecological Modelling 2009; 220: 2068-2075

11 Harley RA, Tozer $K$, Doust J. An analysis of movement patterns and physiological strain in relation to optimal positioning of association football referees. In: Spinks W, Reilly T, Murphy A (eds.). Science and Football IV. London: Routledge, 2002; 137-143

12 Harriss DJ, Atkinson G. Update - ethical standards in sport and exercise science research. Int J Sports Med 2011; 32: 819-821

13 Hoare K. Physiological demands of NRL match officiating. J Aust Strength Cond 2008; 16: 38-42

14 Jennings D, Cormack S, Coutts AJ, Boyd L, Aughey RJ. The validity and reliability of GPS units for measuring distance in team sport specific running patterns. Int J Sports Physiol Perform 2010; 5: 328-341

15 Jones AM. Middle- and long-distance running. In Winter E, Jones A, Davison R, Bromley P, Mercer $T$ (eds.). Sport and Exercise Physiology Testing Guidelines - The British Association of Sport and Exercise Sciences Guide. London: Routledge, 2007; 147-154

16 Jones AM, Doust JH. A $1 \%$ treadmill grade most accurately reflects the energetic costs of outdoor running. J Sports Sci 1996; 14: 321-327

17 Kay B, Gill ND. Physical demands of elite rugby league referees: Part one - time and motion analysis. J Sci Med Sport 2003; 6: 339-342

18 Kay B, Gill ND. Physical demands of elite rugby league referees, part two: heart rate responses and implications for training and fitness testing. J Sci Med Sport 2004; 7: 165-173

19 Krustrup P, Bangsbo J. Physiological demands of top-class soccer refereeing in relation to physical capacity: effect of intense intermittent exercise training. J Sports Sci 2001; 19: 881-891

20 Krustrup P, Helsen W, Randers MB, Christensen JF, Macdonald C, Rebelo $A N$, Bangsbo J. Activity profile and physical demands of football referees and assistant referees in international games. J Sports Sci 2009; 27: 1167-1176

21 Lee RY, Laprade J, Fung EH. A real-time gyroscopic system for threedimensional measurement of lumbar spine motion. Med Eng Phys 2003; 25: 817-824

22 Mallo J, Navarro E, Garcia-Aranda J, Gilis B, Helsen W. Activity profile of top-class association football referees in relation to performance in selected physical tests. J Sports Sci 2007; 25: 805-813

23 Macleod H, Morris J, Nevill A, Sunderland C. The validity of a nondifferential global positioning system for assessing player movement patterns in field hockey. J Sports Sci 2009; 27: 121-128

24 Martin J, Smith NC, Tolfrey K, Jones AM. Activity Analysis of English premiership rugby football union refereeing. Ergonomics 2001; 44: 1069-1075 
25 McLellan CP, Lovell DI, Gass GC. Performance analysis of elite rugby league match play using global positioning systems. J Strength Cond Res 2011; 25: 1703-1710

26 Petersen C, Pyne D, Portus M, Dawson B. Validity and reliability of GPS units to monitor cricket-specific movement patterns. Int J Sports Physiol Perform 2009; 4: 381-393

27 Portas MD, Harley JA, Barnes CA, Rush CJ. The validity and reliability of $1-\mathrm{Hz}$ and $5-\mathrm{Hz}$ global positioning systems for linear, multidirectional, and soccer specific activities. Int J Sports Physiol Perform 2010; 5: 448-458

28 Rampinini E, Coutts AJ, Castagna C, Sassi R, Impellizzeri FM. Variation in top level soccer match performance. Int J Sports Med 2007; 28: 1018-1024

29 Sykes D, Twist C, Hall S, Nicholas C, Lamb K. Semi-automated timemotion analysis of senior elite rugby league. Int J Perform Anal Sport 2009; 9: 47-59

30 Sykes $D$, Twist C, Nicholas C, Lamb K. Changes in locomotive rates during senior elite rugby league matches. J Sports Sci 2011; 29: 1263-1271
31 Townshend AD, Worringham CJ, Stewart IB. Assessment of speed and position during human locomotion using nondifferential GPS. Med Sci Sports Exerc 2008; 40: 124-132

32 Waldron M, Twist C, Highton J, Worsfold P, Daniels M. Movement and physiological match demands of elite rugby league using portable global positioning systems. J Sports Sci 2011; 29: 1223-1230

33 Weston M, Castagna C, Impellizzeri FM, Rampini E, Abt G. Analysis of physical match performance in English Premier League soccer referees with particular reference to first half and player work rates. J Sci Med Sport 2007; 10: 390-397

34 Weston M, Drust B, Gregson W. Intensities of exercise during matchplay in FA Premier League referees and players. J Sports Sci 2011. 29: $527-532$

35 Witte TH, Wilson AM. Accuracy of WAAS-enabled GPS for the determination of position and speed over ground. J Biomech 2005; 38: $1717-1722$ 